\title{
Rancho, plomo y candela. Crónica y ficción en Salsa y Control de José Roberto Duque.
}

\section{Resumen}

Salsa y Control, texto híbrido, fragmentario, trabaja con el cancionero popular y relatos de la vida cotidiana de Caracas. Desdibuja límites entre cultura oral y cultura escrita, sujeto autorizado y sujeto representado. La vida urbana, el exceso de los cuerpos y de la violencia, se traman entre ficción y crónica adoptando el gesto costumbrista e innovándolo con letras de salsa. Abordaré los usos de la misma en la representación de los cuerpos de sujetos, atravesados por el ritmo urbano violento y la relación entre la salsa- que involucra libertad corporal, erotismo - y el control, de ciudad que los vigila a través de sus instituciones.

Palabras claves

salsa y control, Duque, crónica, ciudad, violencia.

\begin{abstract}
Salsa and Control, a hybrid, fragmentary text, works with the popular song book and stories of everyday life in Caracas. It blurs limits between oral culture and written culture, authorized subject and represented subject. Urban life, the excess of bodies and violence, interweave fiction and chronicle adopting the usual manners and renewing them with salsa lyrics. I will approach the uses of the same in representation of the subjects 'bodies, traversed by the violent urban rhythms and the relationship between the salsa - that involves body freedom, erotism -and the control, a city that watches them through its institutions.
\end{abstract}

Keywords salsa and control, Duque, chronicle, city, violence. 


\section{La complejidad del género}

Entre fines del Siglo XX y principios del siglo XXI asistimos a un resurgimiento de narrativas que ponen en evidencia la realidad de las urbes actuales, realidad que muchas veces cuestiona las posibilidades de representación del lenguaje. La prosa cronística hoy asume el desafío de contarla al relocalizar las voces de sujetos excluidos y marginados que las habitan, con la impronta de una marcada vocación estética del autor.

La crónica posee una compleja estructura narrativa que subyace en la mezcla de géneros discursivos y en la incorporación de la oralidad en el relato (Perilli). Se trata de un espacio textual impreciso que impugna la taxonomía de los géneros mientras se apropia de todos a la vez. Juan Villoro en su brillante texto "La crónica, el ornitorrinco de la prosa" (2006) ha otorgado una de las más difundidas definiciones de la misma, y quizás sea ésta una de sus figuraciones más precisas. El autor acude a la metáfora del animal heterogéneo para dar cuenta de una escritura que se cifra en la mixtura de formas que la constituyen como un género híbrido. De este modo, al llamarla "el ornitorrinco de la prosa", logra manifestar este carácter múltiple de un texto autónomo que resulta de la reelaboración del enorme "catalogo de influencias" literarias que absorbe. Vale la pena retomar sus palabras:

De la novela extrae la condición subjetiva la capacidad de narrar desde el mundo de los personajes y crear una ilusión de vida para situar al lector en el centro de los hechos; del reportaje, los datos inmodificables; del cuento, el sentido dramático en espacio corto y la sugerencia de que la realidad ocurre para contar un relato deliberado, con un final que lo justifica; de la entrevista, los diálogos; y del teatro moderno, la forma de montarlos; del 
CATEDRAL TomAda: Revista de crítica literaria latinoamericana / Journal of Latin American Literary Criticism Rancho, plomo y candela. Crónica y ficción en Salsa y Control de José Roberto Duque.

teatro grecolatino, la polifonía de testigos, los parlamentos entendidos como debate: la "voz de proscenio" , como la llama Wolfe, versión narrativa de la opinión pública cuyo antecedente fue el coro griego; del ensayo, la posibilidad de argumentar y conectar los saberes dispersos; de la autobiografía, el tono memorioso y la reelaboración en primera persona. (Villoro 579)

Es, en definitiva, un entramado polifónico que exhibe la condición compleja de lo narrado. Si bien la referencialidad es parte constitutiva de la crónica y de allí su anclaje periodístico, lo literario se manifiesta en el "gesto de diferenciación que permite reconfigurar la realidad empírica desde una mirada otra que resiste al relato de lo real, entendiendo lo real como solo enunciado de los hechos"(Monsiváis ctd. en Falbo 14).

Entre los múltiples desarrollos teóricos existentes, adhiero a la propuesta de Susana Rotker quien define la crónica como un espacio textual híbrido o mixto, que es a la vez marginado y marginal porque ocupa un lugar incierto en las fronteras entre el periodismo y la literatura. Este género convoca, según la autora, tres condiciones para su existencia. La referencialidad y la actualidad, es decir, el necesario anclaje en la realidad y la alusión directa a hechos coyunturales o mediatos que se presentan como elementos propios de lo periodístico, y la autonomía literaria, es decir, el valor textual que revelan como material literario una vez que los hechos narrados perdieron toda significación inmediata por el paso del tiempo. Esta última también está dada por la estilización que ejerce la presencia de un sujeto literario y los recursos utilizados (2005).

Es desde este acecho a lo real, que entre los múltiples discursos sociales que involucra, la crónica se apropia del testimonio para da cuenta de hechos que no son dichos desde los discursos oficiales y desde esa toma de posición política registra "la experiencia del aislamiento de grupos marginales y negados por el sistema central" (Nofal 28) y lo hace desde un trabajo estético a partir del 
lenguaje. En este sentido el testimonio, se vuelve "el estímulo cardinal de la crónica" (Villoro 579), en tanto constituye una de las materias primas del relato.

Salsa y Control $^{1}$ (1996) del periodista y escritor venezolano José Roberto Duque es un texto híbrido, que procede de modo fragmentario, trabajando con letras del cancionero popular caribeño y relatos de escenas de la vida cotidiana de los barrios urbano-marginales ${ }^{2}$ de Caracas. En el texto se desdibujan los límites entre cultura oral y cultura escrita, sujeto autorizado y sujeto representado. La marginalidad estragada por la violencia, la droga, el abuso de alcohol y la falta de oportunidades económicas, ocupan todo el espacio de la representación textual. El relato de la vida urbana, el exceso de los cuerpos y el exceso de la violencia, se traman entre diferentes modulaciones de ficción y la crónica adoptando el gesto costumbrista e innovándolo con la introducción de las letras de la salsa. La música por tanto se convierte en un elemento central del relato en la medida en que otorga una organización interna o mejor dicho un ritmo particular al universo textual que insiste en el corte abrupto, la irrupción, la variación, la elipsis. Duque presenta un texto que resiste cualquier encasillamiento genérico en la medida en que entra y sale de todos al mismo tiempo, es uno y muchos textos a la vez. Sin embargo, su totalidad se sobrepone al fragmentarismo demostrando una cohesión interior profunda. ${ }^{3}$

${ }^{1}$ Este texto ha sido editado en versión impresa por la editorial Monte Ávila en 1996 pero el autor ha dispuesto en su blog personal una copia gratuita. El mismo afirma en su sitio "Léalo, imprímalo y compártalo libremente, pero por favor no lo comercialice. La cultura es un espacio para la libertad; vamos a ejercerla responsablemente". Este trabajo sigue la versión web por lo que no se explicitan números de página en el citado.

${ }^{2}$ Entiendo por zona urbano marginal un territorio geográfico donde se produce una concentración espontánea de población en puntos del territorio con densidades relativamente altas en comparación; escenario social donde los sujetos no cuentan condiciones materiales y simbólicas que garanticen su plena integración social. (Enríquez 54)

${ }^{3}$ Salsa y control es abordado desde diferentes perspectivas por los siguientes autores: González González, Daniuska en "En el nombre del ladre, del tiro y del espíritu landro. Salsa y control, de José Roberto Duque" revisa las estrategias de representación de la violencia; Maguette Dieng en "Poema musical y ficción en Salsa Y Control, del Venezolano José Roberto Duque" se centra en el estudio del uso que hace del poema musical para construir los relatos; Luisa Elena Pinel trabaja los personajes femeninos en la obra en "Lo femenino a la sombra en salsa y control y no escuches su canción de trueno de José Roberto Duque"; Rebecca Jarman ha escrito 'Entre la injuria, la calumnia y la discordancia: The Spectacle of Alienation in José Roberto Duque's Salsa y control (1996)' y 'La cultura masiva y la alienación en Salsa y control (1996) de José Roberto Duque". 


\section{La música, el ritmo del relato}

El texto huye de la linealidad y lleva al lector al ritmo de una danza caótica que es imposible reproducir. Se pueden reconocer dos partes de la obra: la primera, precedida por una intro, en la que se entrelazan las historias de variados personajes de la vida diaria de la periferia caraqueña, y la segunda, en la que el autor realiza una alusión explícita a los sucesos históricos ocurridos en Venezuela en Febrero de 1989; entre ambas partes se encuentra un interludio. Este modo particular de organizar el texto al incorporar la intro y el interludio, formas propias de ciertas obras musicales, da cuenta de una clara intención de Duque de construir desde lo literario una obra musical que logre también transmitir a partir de su estructura, el ritmo que contiene al interior de sus páginas.

El autor adopta diferentes estrategias para ingresar la salsa en el relato: incorpora letras completas, versos sueltos, fragmentos, a veces lo hace a modo de epígrafe, encabalgando versos en el relato, otras veces la salsa es evocada por los personajes. La música no funciona como elemento aislado sino que es el entramado profundo del texto en la medida en que se permite reflexionar sobre la vida, la muerte, el goce y el dolor, es a la expresión de la comunidad toda: "Toma sus sueños raídos/los parcha con esperanzas ... Ruben Blades. Pablo Pueblo"; "ni hay respuesta/ a la pregunta:/ ¿Para qué uno muere? Ruben Blades. Agua de Luna".

La obra se abre con una intro en que transcribe la letra íntegra de la canción "Sujétate la lengua" que propone que "ya no se puede vivir en el ambiente social/ la discordancia no deja na'/vive tu vidal y no digas na'/lengüetero/ sujétate la lengua/ sujétala." y aporta una clave de lectura: en los relatos siempre están presentes el chisme, el rumor, la delación, el malentendido, pero a la vez, aquella canción atrapa una profunda ironía, no se puede callar al pueblo.

La presentación de un destinatario puntual a quien llama "extranjero" en "Noche de línea de luz" el primer relato, evidencia el juego simultaneo de 
seducción y traición que pone en funcionamiento el autor: por un lado se apropia de formas populares como la salsa, intenta borrar las jerarquías, pero inmediatamente restituye las diferencias que distinguen a los textos de esos márgenes (Amar Sánchez). El texto seduce y encanta al lector por el placer de lo popular y lo conocido, al mismo tiempo que traiciona: integra las formas masivas al relato, pero no puede evitar marcar la diferencia con esa "otra cultura", en un claro gesto de contacto y distancia. El extranjero es ese otro, ajeno al espacio del barrio marginal, del que el autor pretende distanciarse.

Los usos de la salsa articulan los relatos de múltiples maneras. La música invade los barrios de Caracas a la vez que los construye, son para el autor "concentración de sonidos y colores". En cada espacio de "callejones, ranchos y retorcimientos" los sonidos aparecen acompañando el ritmo de la vida cotidiana y penetran en el cuerpo de los sujetos. La "cancha" es lugar del encuentro de la multitud que se reúne "a descargar hasta que la piel aguantara"(3), es a la vez, el espacio predilecto de la fiesta colectiva y del enfrentamiento policial. El control institucional que se ejerce sobre los cuerpos que danzan y se erotizan, intenta ser quebrantado por aquellos que se violentan "Además se contaba con la destreza relampagueante del punzón bajo el costado; la multitud estaría absorta en la música, no se vería la sangre y un tipo en el suelo es un tipo más".

Los sujetos representados se encuentran permanentemente en situaciones de extrema violencia, bien como testigos o protagonistas de crímenes, saqueos, asesinatos y la música envuelve cada episodio violento "Sintió el olor sulfatado del arma, su gélida firmeza rozándole el cutis bañado en gotas de miedo, la mano izquierda de Tabaco atenazándole el cuello, y después el rugido de la pólvora que desgarró la música lejana" y al mismo tiempo se encarna en los personajes que "sienten la alucinación del poder multiplicada por el ron y el polvo, magnificada por la melodía de metales y cueros para insuflarse los ánimos”. La salsa atraviesa la vida de los habitantes del barrio, sus sonidos acompañan la celebración de la vida y también la muerte "No quiero que nadie llore/ si yo me muero mañana/ ay que me lleven cantando salsa”. 
Entre la primera y la segunda parte de la obra, se encuentra un interludio, representado con letra completa de una salsa titulada "Sobre una tumba humilde" de Tite Curet Alonso. La pieza alude a la muerte del hombre pobre que no puede ser homenajeada mas que con el recuerdo y el amor "Yo no te puedo hacer un monumento/de mármol con inscripciones a colores/ pero a tu final morada vengo atento/ sembrando una flor silvestre y mil amores/". Asimismo la aparición de un nos inclusivo más adelante propone pensar que de un modo representa las múltiples voces insertas en el relato "Porque nosotros, los que llevamos por bandera,/ por estandarte, la condición de la pobreza/ cuando queremos nuestra pasión es verdadera/ no hay quien nos gane: amar es nuestra gran riqueza". Al mismo tiempo esta canción anuncia la presencia de la muerte en los relatos posteriores en los que el autor recrea los hechos históricos conocidos como "el Caracazo" de suma importancia para el pueblo venezolano. Fue una rebelión popular desatada en la ciudad capital el 27 y 28 de febrero del 89 en respuesta a los ajustes económicos aplicados por el gobierno de Carlos Andrés Pérez bajo la presión del Fondo Monetario Internacional. El estallido fue reprimido brutalmente dejando un tendal de víctimas fatales a la vez que condujo a la suspensión de las garantías constitucionales (Ansaldi y Giordano). Se trató de un acto de resistencia ante la imposición de medidas neoliberales por parte del FMI.

En la segunda parte de la obra, el relato "Adioses" se distancia de los demás por diferentes razones: aparecen personajes que no habían aparecido aún, se especifica la fecha en que se sitúan los hechos narrados y fundamentalmente, cambia de modo radical el modo de contar la historia. Tres personajes van entrecruzando sus voces fragmentariamente desde distintos tiempos y lugares. Hay un ritmo vertiginoso en la fragmentariedad del relato y corresponde al lector tejer los hilos de la historia privada de César que es también la historia pública que vivió el pueblo venezolano los días 27 y 28 de Febrero de 1989. El testimonio de este personaje desata la trama de la historia, cuenta el hartazgo del pueblo ante la crisis político-económica y la falta de identidad ante el canto patrio; anuncia también la llegada de otro momento histórico : 
Eso de meterle el pecho a un tanque blindado en plena avenida soleada no parece cosa de locos, de drogos ni de enguayabados -pinga-. Más bien parece que no funcionó la burda treta gubernamental aquella: cuando descubrieron que a la gente del cerro se le alteraba el color al escuchar el canto patrio (aquel Gloria al Bravo Pueblo), entonces decretaron cantárselo cinco y seis veces al día, Glorialbravopueblo, Glorialbravopueblo, Glorialbravopueblo, hasta que la gente de tanto repetir y balbucear el estribillo terminó por hastiarse y mandarlo al carajo. (...) Pero ahora, otras melodías están sonando ¿Cómo irán a cansarnos de ella?

La música, en este caso el Himno Nacional, se presenta como otro mecanismo de control por parte del Estado, como si la repetición hasta el hartazgo del mismo lograra por sí sola la cohesión social. Sin embargo, las "otras melodías" que oye César expresan metafóricamente al pueblo que se levanta en resistencia. La inclusión de la pregunta retórica le otorga contundencia al enunciado que adquiere un fuerte tono desafiante.

La voz de César se va apagando lentamente hasta la muerte y son sus compañeros los que continúan su relato. Aníbal, relata la vida de César, como militante que había huido en nombre de la revolución a la selva en el 78 y que había recorrido el país anunciando que era necesario el colapso del sistema y el triunfo de la lucha popular que él encabezaba. Durante ese itinerario César contrajo lepra y su terrible estado de salud lo obligó a volver al barrio. Avergonzado por su visible enfermedad acabó sus días encerrado pero vivió para ver que su anuncio se había cumplido. Jorgecito reconstruye la marea de saqueos, asesinatos, asaltos armados a los bloques, el olor de los cadáveres que se iban descubriendo y los últimos momentos de vida de César hasta su suicidio, abatido por su enfermedad y el asesinato de su novia. 
Tanto Aníbal como Jorgito destacan la pasión de César por la rumba y cuentan cómo quiso devolverle la alegría al barrio poniendo máximo volumen desde su casa solitaria. Pero ante la desmesura de muerte y horror, la música para quienes habitan el barrio ya no significa lo mismo: "Así que sacudidos como estamos por la sorpresa, al escuchar la música nadie ríe, nadie baila, nadie canta, por supuesto, pero al mismo tiempo, pero qué aliento, qué gusto a combate ganado sentimos todos desde la cancha hasta el último apartamento del bloque" (30). A pesar del espanto los personajes vislumbran en medio de tanta tragedia la posibilidad de un futuro mejor, como si fuera necesario pasar por eso. Resulta muy interesante la intervención entre las voces de Rubén Blades a través de una canción suya "No se puede querer a la caína", que en el texto funciona claramente como una declaración de principios de César que antes de morir coloca esa canción para que la oiga todo el barrio, sabiendo que a la "malandrería" no le cae bien dada su alusión en contra de la droga; de ahí que luego de recitar todos sus males el estribillo repite "No se puede querer a la caína".

Los siguientes relatos de la segunda parte retoman las historias y personajes de la primera y el último llama especialmente la atención por su dedicatoria: "Dedico esta especie de relato a los 247 muertos oficiales y a los otros miles de de muertos (extraoficiales pero muertos al fin) del 27 de Febrero de 1989". Al definir el texto como "esta especie de relato" Duque nos coloca en una encrucijada en relación al género tan difícil de definir en esta obra, pero a la vez podemos advertir como el espacio de la representación se vuelve un lugar de encuentro y negociación entre las formas populares y literarias (Amar Sanchez). Hacia el final se retoma la historia personal de Elisa, personaje que protagoniza el primero, pero esta vez su historia es la historia de todos luego de lo que pasó en Febrero. El control está presente entre los pobladores de los bloques, ya nada es lo mismo donde "todo caminante nocturno se siente observado" pero la salsa, tarareada por Elisa, les devuelve la fe en la justicia "Justicia tendrán, justicia verán/ en el mundo los desafortunados./ Con el canto del tambor/ del tambor/ la justicia yo reclamo." 
De modo tal que las múltiples discursividades que se superponen $\mathrm{y}$ dialogan, constituyen el espesor del texto que no se asimila a límites precisos ni pretende un discurso monológico y cerrado. Por el contrario, los personajes, las historias narradas "pierden su dimensión singular y se transforman en memoria colectiva, en testimonio de lo compartible, de lo que une en la miseria, en el dolor, en la fiesta, en el gozo" (Reguillo 45).

A través del uso de la salsa, Duque realiza un movimiento de descentralización de la ciudad de Caracas y pone en foco los barrios periféricos “Caracas estaba muy abajo, ciega y la autoridad de uniforme era una pesadilla abisal, una saeta que hería débilmente, desde muy lejos". El texto identifica a la zona baja de Caracas con el poder policial y el control, mientras que el escenario de sus historias, la periferia, es un "planeta de rancho, plomo y candela", expresión que metonímicamente alude a la pobreza, la violencia y la música. En palabras de Ana María Amar Sánchez:

Como sabemos, las ciudades también se también se construyen en los libros, es más, muchas veces nuestras imágenes de ellas nacieron en los textos. Se crean allí imaginarios, se configuran espacios, ciudades que definen identidades históricas y culturales. La imagen construida se impone a veces con más fuerza que la experiencia.(...) Casi siempre la literatura ha configurado ciudades donde es posible reconocerse, ciudades con marcas de identidad, pero no por eso menos "reales". (157).

Duque recrea los espacios marginales de Caracas y construye un imaginario que define las identidades históricas y culturales de los sujetos representados. Ofrece una cartografía urbana que sus personajes construyen con sus prácticas cotidianas (De Certeau). La sintaxis de la música va proponiendo diferentes andares de las dos ciudades que coexisten en el universo textual: la ciudad real, Caracas, capital de Venezuela, y sus barrios, centros del relato y la ciudad escrita que articula sus inventarios con signos textuales y léxicos que 
tienen sentido literario y que pueden carecer de sentido arquitectónico o urbano equivalente (Sarlo). En el intersticio entre ambas los sujetos modelan un imaginario de la ciudad al ritmo de la vida cotidiana y de la salsa.

Susana Rotker siguiendo a García Canclini opina que la violencia produce crisis en todos los órdenes, también en el del discurso; quizás porque la ciudad actual no puede ser narrada como a principios de Siglo (2001). Duque nos propone una nueva cartografía de Caracas desde su proceder fragmentario. El recorrido por Salsa y Control nos acerca a los usos de la salsa en la representación de los cuerpos de los sujetos, atravesados por el ritmo urbano violento y la singular relación entre la salsa-una música que remite a la libertad de los cuerpos, al erotismo y al exotismo tropical - y el control, que los vincula con una ciudad que los controla a través de sus instituciones.

\section{Bibliografía}

Ansaldi, Waldo y Giordano Verónica. América Latina la construcción del orden: de las sociedades de masas a las sociedades en proceso de reestructuración Buenos Aires: Ariel, 2012.Impreso.

Amar Sanchez, Ana María. Juegos de seducción y traición. Literatura y cultura de masas. Rosario: Beatriz Viterbo Editora, 2000. Impreso.

De Certau, Michel. La invención de lo cotidiano. Artes de hacer. México: Universidad Iberoamericana, 1996. Impreso.

Duque, José Roberto. Salsa y Control. Disponible en http://salsaycontrol.blogspot.com.ar/. web 
Enríquez, Pedro Gregorio. "El espacio urbano como lugar de marginalidad social y educativa" http://www.argonautas.unsl.edu.ar/files/04\%20Enriquez.pdf consultado 12/2/2014.

Foucault, Michel. Vigilar y castigar. Nacimiento de la prisión. Buenos Aires: Siglo XXI editores, 2012. Impreso.

Nofal, Rossana. La escritura testimonial en América Latina. Argentina: UNT, FFyL, 2002. Impreso.

Perilli, Carmen. Catálogo de ángeles mexicanos: Elena Poniatowska. Rosario: Beatriz Viterbo Editora, 2006. Impreso.

Reguillo, Rossana. "Textos fornterizos. La crónica, una escritura a la intemperie". Tras las huellas de una escritura en tránsito. Comp. Falbo, Graciela. Buenos Aires: Al Margen, 2007. Impreso.

Rotker, Susana (ed.) Ciudadanías del miedo. Colombia: Rutgers Univ/Nueva Sociedad, 2001. Impreso.

La invención de la crónica. México: Fondo de Cultura Económica, 2005. Impreso.

Sarlo, Beatriz. La ciudad vista. Mercancía y cultura urbana. Buenos Aires: Siglo Veitiuno Editores, 2009. Impreso.

Villoro, Juan, "La crónica, el ornitorrinco de la prosa". Antología de la crónica latinoamericana actual. Ed. Jaramillo Aguedo, Darío. Buenos Aires: Alfaguara: 2012. Impreso. 